DOI: $10.12957 /$ demetra.2016.14375

\title{
Mudanças nos hábitos alimentares do caboclo de Chapecó-SC
}

\section{Alimentarian habits of the caboclos from Chapecó-SC, Brazil}

Lucia Chaise Borjes'

Camila Lazarin ${ }^{2}$

Michele Carla Marcon²

1 Universidade Comunitária da Região de Chapecó, Curso e Nutrição. Núcleo de Estudos e Pesquisas em Alimentação e Nutrição. ChapecóSC, Brasil.

${ }^{2}$ Universidade Comunitária da Região de Chapecó, Curso e Nutrição. Chapecó-SC, Brasil. Chapecó-SC, Brasil.

Correspondência / Correspondence Lucia Chaise Borjes

E-mail: Ibories@unochapeco.edu.br

\section{Resumo}

$\mathrm{O}$ ato de se alimentar diz respeito à cultura e deve ser levado em consideração para avaliar as modificações ocorridas durante os processos de industrialização. Este estudo teve por objetivo mostrar as modificações dos hábitos alimentares dos caboclos de uma região do Oeste de Santa Catarina, identificando as diferenças e semelhanças nesse processo e sua ligação cultural. Trata-se de pesquisa exploratória de caráter descritivo e abordagem qualitativa. Foram realizadas entrevistas individuais, norteadas por uma questão inicial referente aos hábitos alimentares passados e atuais. A análise foi realizada pelo método de análise descritiva. Observou-se que os caboclos não consomem todas as preparações que consumiam na infância, mas, quando possível, elaboram as preparações recordando-se desta, enfatizando que os alimentos produzidos e consumidos naquela época eram de maior valor nutritivo e com menor probabilidade de desenvolverem patologias. Desse modo, pode-se concluir que o caboclo ainda permanece ligado a suas raízes alimentares.

Palavras chave: Comportamento Alimentar. Hábitos Alimentares. Grupo Social. Grupos Étnicos. Pesquisa Qualitativa.

\section{Abstract}

The act of feeding concerns culture and should be taken into account to assess the changes occurred in the process of industrialization. This study aimed to show the changes in eating habits of the caboclo from a region of West Santa Catarina 
state, Brazil, identifying the differences and similarities in the process and their cultural connection. It is exploratory descriptive research with qualitative approach. Individual interviews, guided by an initial question of past and current eating habits were conducted. The analysis was performed by the method of descriptive analysis. It was observed that the caboclos do not consume all the preparations consumed in childhood, but, where possible, they elaborate preparations remembering this, emphasizing that the food produced and consumed at that time were of higher nutritional value and less likely to develop diseases. Thus, it can be concluded that the caboclos remain connected to their food roots.

Key words: Feeding Behavior. Food Habits. Social Group. Ethnic Groups. Qualitative Research.

\section{Introdução}

A história do homem se confunde com a história da alimentação. ${ }^{1}$ Assim, a alimentação constitui uma das atividades humanas mais importantes, não só por razões biológicas evidentes, mas também por envolver aspectos econômicos, sociais, científicos, políticos, psicológicos e culturais fundamentais na dinâmica da evolução da sociedade. ${ }^{2}$

Em décadas anteriores, $o$ ato de alimentar-se envolvia toda uma simbologia caracterizada por determinado grupo. Muitas comunidades foram estudadas por antropólogos e sociólogos em razão de sua cultura e ao fato de estarem susceptíveis a mudanças ou miscigenações em seus hábitos. ${ }^{3}$ Segundo Canesqui, "as populações urbanas e rurais são estudadas na perspectiva da comunidade de que estão submetidas, enquanto agrupamento homogêneo e orgânico da vida social que poderia ou não estar submetido a processos de mudança que o desintegrasse".

A Antropologia estuda as dimensões culturais expressas nos padrões, crenças, ideias e pensamentos da comunidade. Segundo Murrieta, ${ }^{5}$ "os estudos antropológicos sobre hábitos alimentares concentram-se, principalmente, em análise mononivelares de estruturas mentais e sociais, sistemas de representação e infraestrutura econômico-ambientais".

As escolhas alimentares de determinadas comunidades apresentam-se como resultado da interação entre a estrutura social, os habitus e as condições materiais das práticas cotidianas de 
uma sociedade. ${ }^{6}$ Assim, Fischler (apud Figueroa, 2004) ${ }^{3}$ indica que a Antropologia relaciona os hábitos alimentares conforme a cultura dos povos:

Os estudos antropológicos que abordam o tema dos hábitos alimentares (influenciados pelos gostos e vontades) demonstram que o que se come e como se come são elementos fortemente incorporados na construção da identidade cultural dos povos, constituindo uma das mais fortes barreiras de resistência às mudanças. De certa forma, os alimentos representam a ligação mais primitiva entre natureza e cultura, fazendo parte da raiz que liga um povo, uma comunidade ou um grupo à sua terra è "alma" de sua história (Fischler apud Figueroa, 2004, p. 105-106). ${ }^{3}$

Na mesma direção, Alessi ${ }^{7}$ afirma que desde as origens da sociedade brasileira até hoje, o processo de aculturação, que expressa o contato entre diferentes culturas, sempre desempenhou importante papel, prescrevendo normas e valores da conduta alimentar. Cada região do país foi marcada por uma miscigenação de culturas. Pode-se dizer que a construção da cozinha de um país colonizado seja descrita como um somatório de influências. Entretanto, o processo é complexo e implica confrontos, associações e exclusões.

Se, de modo geral, as populações que se deslocaram para as Américas trouxeram com elas seus hábitos, costumes e necessidades, é importante destacar que as várias influências não são meras "contribuições", mas fazem parte de um processo colonial que confrontou povos diferentes e, consequentemente, sistemas alimentares muito diversos. ${ }^{8}$

O Oeste catarinense fez parte de um caminho que ligava o estado do Rio Grande do Sul ao de São Paulo, por onde os tropeiros passavam na busca de gado e animais de carga, utilizados pelos fazendeiros no transporte de café. A colonização trouxe ao Oeste catarinense um estilo de vida diferente, influenciado pelos imigrantes, geralmente de origem italiana e alemã, vindos do Rio Grande do Sul. Instalaram-se empresas colonizadoras, que tomaram posse das terras tidas como mais produtivas com o objetivo de comercializá-las. Os índios e caboclos que estavam com a posse dessas terras, mas que não possuíam meios legais para continuar nelas, foram forçados a se retirar das terras, deslocando-se a regiões menos férteis, em morros e encostas. ${ }^{9}$

Nessa região, o caboclo é considerado "o segundo brasileiro. O primeiro é o índio". "Ele não tem origem, como os italianos e os alemães. Ele é brasileiro. É do Brasil”. Quando solicitado a explicitar no que consiste o caboclo, não remetem a uma gênese, mas lembram que "caboclo é uma mistura de raça, de pessoas de coragem, de fazer o bem”. É nesse sentido que afirmam: "sou caboclo com muita honra. Não corro atrás do dinheiro. Faço pra viver". Ou, "a filosofia de caboclo é vontade de viver, não devendo para branco". ${ }^{10}$ 
Nos diversos grupos, inclusive os caboclos, os padrões alimentares sustentam a identidade coletiva, posição na hierarquia, na organização social. Mas, também, determinados alimentos são centrais para a identidade individual.

A alimentação é uma necessidade básica, um direito humano e, simultaneamente, uma atividade cultural. Comer não representa apenas o fato de incorporar elementos nutritivos importantes para o nosso organismo; é antes de tudo um ato social e, como toda relação que se dá entre pessoas, traz convívio, diferenças e expressa o mundo da necessidade, da liberdade ou da dominação. ${ }^{11}$

As atitudes em relação à comida são normalmente aprendidas cedo e bem, e são, em geral, inculcadas por adultos afetivamente poderosos, normalmente a figura materna, o que confere ao nosso comportamento um poder sentimental duradouro. ${ }^{12}$ Segundo Marciel, ${ }^{13}$ as lembranças da comida da mãe envolvem emoções, um toque íntimo na preparação que é feita e como ela é preparada.

Nesse contexto, buscou-se conhecer os hábitos alimentares do caboclo de Chapecó, alimentos de sua cultura que seus pais e avós consumiam e que permanecem inseridos na alimentação habitual, identificando diferenças e semelhanças nesse processo e sua ligação cultural. Ou, ainda, conhecer os aspectos que caracterizam essa cultura com o intuito de estudar a permanência dos hábitos alimentares na cultura cabocla de maneira mais detalhada.

\section{Metodologia}

Este estudo foi realizado com caboclos residentes no município de Chapecó, participantes da Associação Puxirão dos Caboclos, com sede no bairro Efapi, que possui em média 500 associados. Destes, aproximadamente 30\% têm idade acima de 55 anos. A amostra foi constituída por $20 \%$ dos caboclos com mais de 55 anos, de ambos os sexos, totalizando 30 indivíduos. Trata-se de uma pesquisa exploratória, com caráter descritivo e abordagem qualitativa.

A pesquisa foi realizada através de visitas nas casas de cada participante, com entrevista individual, norteadas por uma questão inicial: "Quais os alimentos que você consumia quando criança e que você e sua família continuam consumindo?".

O estudo teve aprovação do Comitê de Ética em Pesquisa com Seres Humanos da Universidade Comunitária da Região de Chapecó com parecer n. 031/2010. Todos os participantes foram informados sobre o objetivo geral do estudo e seus direitos de confidencialidade e não obrigatoriedade em responder às perguntas, uma vez que as entrevistas foram gravadas. Mediante aceite de participação, todos assinaram o Termo de Consentimento Livre e Esclarecido.

As gravações foram transcritas como declaradas nas entrevistas, e a análise dos dados foi realizada por método de análise descritiva. 
Analisar o discurso seria dar conta de relações históricas, de práticas muito concretas, que estão vivas nos discursos. É como se no interior de cada discurso, ou num tempo anterior a ele, se pudesse encontrar, intocada, a verdade, despertada então pelo estudioso. ${ }^{14}$

\section{Resultados e Discussão}

Pesquisar a alimentação em um contexto cultural é como conhecer a identidade de um povo, ou grupo social. O caboclo dos dias atuais não está distante daquele dos períodos da colonização. Ele procura trabalhar para subsistência. Mesmo que $50 \%$ dos entrevistados estejam residindo nas cidades, continuam ligados aos costumes em que foram criados. Entre os caboclos que residem no meio rural, nota-se que trabalham para sobreviver, e o respeito à natureza os diferencia da maioria da população capitalista. ${ }^{9}$

Os caboclos relataram consumir no almoço, quando crianças, os seguintes alimentos: arroz, feijão, mandioca, macarrão caseiro, polenta, canjica, batatinha e quirera. De acordo com Maciel \& Menasche, ${ }^{8}$ quando queremos fazer referência ao cotidiano, a algo comum, familiar, repetido, rotineiro, dizemos: é feijão-com-arroz. Essa metáfora surge e ganha sentido pelo fato de que, no país, uma grande parcela da população come arroz e feijão diariamente.

Na hora do almoço, utilizavam como suco "a água de rapadura”, ou seja, o caldo de cana. A carne de porco era a mais consumida, além de galinha e gado. A carne de porco era, também, amplamente utilizada em preparações, como o salame. Dela também era feita a banha, na qual fritavam a carne e colocavam tudo em latas para conservar. A carne era tirada da banha e aquecida, pronta para o consumo. Esquentavam o pedaço cortado ao meio acompanhado com mandioca e feijão. O feijão era temperado utilizando conchas de banha. Para conservar, também faziam charque.

Preparavam também o churrasco na brasa, tanto com o charque como com outras carnes, da seguinte maneira: pegavam a carne e jogavam na brasa. Após a cocção, colocavam em cima da mesa e batiam as cinzas da carne para posterior consumo. Relataram que hoje não pode ser feito desta maneira, porque é proibido pela vigilância sanitária. Alguns entrevistados afirmaram comer peixe nos finais de semana, pescado por eles. Outros relataram consumir carne quando adquiridas em troca de serviços, geralmente a carne de gado.

Os animais eram criados soltos no pátio. Da vaca tiravam o leite e faziam o próprio queijo. Segundo Lucas \& Perin, ${ }^{9}$ toda família auxiliava no cuidado com os animais, que eram criados soltos e serviam para a subsistência e o consumo. Em alguns casos, destacaram as carnes de caça, as quais, segundo o entrevistado, não eram proibidas pela polícia ambiental. 
O desjejum das crianças pequenas era papinha com caldo de feijão e arroz esmagado. No caso dos adultos, era o revirado de feijão com pão, queijo ou ovo frito, bolinho frito, polenta ou polenta frita e carne de porco. Utilizavam bastante a broa feita de farinha de milho. Pamonha, farofa, bolinho de mandioca, batata doce com leite e também a mandioca. Ovo frito com pão e torresmo, açúcar mascavo e salame. Socavam arroz e trigo no pilão ou no monjolo e faziam também casquinhas de trigo para comer com leite. Faziam pão caseiro (trigo/milho) no forno para comer com café e leite de vaca. Café de soja (grãos de soja torrados, socados no pilão e preparados como café) com açúcar mascavo. Cortavam o cuscuz para comer com leite, o qual era preparado com farinha molhada e cozido na tampa da panela que ficava sobre ela mesma. O milho verde era ralado nas latas de azeite e com a massa eram preparados bolo e pamonha. Pão feito na panela.

Além disso, cozinhavam batata doce para comer com carne que tinha sobrado do almoço do dia anterior. Água adoçada com mel de abelha, acompanhada com pão de milho, em que, segundo o entrevistado, oferecia resistência ao organismo para o trabalho braçal. Na época, o desjejum precisava fornecer ao organismo "sustância", para que suportasse o trabalho árduo na lavoura.

Neste conceito de comida, entra um sistema de classificação bastante subjetivo, como forte/fraco. ${ }^{15}$ A comida valorizada, que se dispõe, é aquela "capaz de sustentar o corpo, dar força e energia para trabalhar, a que enche a barriga, deixando a sensação de estar alimentado". ${ }^{2}$

Para confraternizar com vizinhos, matavam porco, fritavam a carne com alho e temperos, e com música festejavam. A salada mais utilizada era o "raditi" (almeirão), ou seja, salada do mato. Eram consumidas frutas, e a mais citada é a banana, que também era consumida com leite. Preparavam pamonhas doces e salgadas, além de geleias caseiras com laranja, abóbora, pinhão, batata-doce e afirmavam que era mais saudável e sinônimo de longevidade. Para comer com pão, utilizavam muito a nata, com a qual faziam manteiga.

Pode-se identificar que o grupo pesquisado refere-se à alimentação como um ato que gira em torno de todo um ritual de preparação.

Alguns entrevistados falaram que, a partir do momento em que vieram para cidade, passaram a adquirir alimentos no supermercado, os quais não são naturais como os que consumiam quando eram crianças, ou seja, possuem a consciência dos danos que o excesso de alimentos industrializados ocasiona ao organismo.

Segundo Moreira, ${ }^{1}$ a influência do novo padrão de alimentação, caracterizado pelo consumo de alimentos comercializados processados e ultraprocessados, também atinge os comensais que vivem nas áreas rurais. Com isso, a identidade alimentar regional tende a apresentar um padrão de consumo que mescla alimentos da terra e alimentos industrializados, tanto nas capitais quanto nas áreas rurais. Isso foi observado no presente estudo, em que os entrevistados relataram ainda comer preparações que estavam habituados, mas com alguns ingredientes industrializados. 
A industrialização em si é percebida como um processo que pode afastar o alimento das pessoas, na medida em que, muitas vezes, dificulta o entendimento da origem dos ingredientes que compõem determinado alimento. ${ }^{2}$

Os alimentos descritos anteriormente faziam parte do dia a dia do caboclo. Hoje, segundo relatos dos caboclos, não dá para fazer a quirera com carne de galinha, pois essa carne "desmancha" na preparação. Afirmam que o arroz, as farinhas de trigo e milho, as carnes, a mandioca, o próprio milho eram mais saudáveis, porque eram naturais, "da colônia". A utilização de ingredientes industrializados pode implicar a adoção ou rejeição de novos hábitos e será também produto da prática e da experiência dos grupos sociais, bem como do que significam para eles. ${ }^{4}$

Como discutido no estudo de Renk \& Salvoldi, ${ }^{10}$ os caboclos valorizam os alimentos que produzem em casa. Quando comentam, recordam que eram mais saborosos, destacando a farinha de beiju, que era fabricada no monjolo, bem como a produção do torresmo e a banha de porco, utilizados também no preparo do feijão.

Colocam que a água não tinha contaminação, e que os antigos diziam que a água corrente podia ser utilizada, mas água parada não, pois água corrente não pegava mal algum. Relatam ainda que a carne era mais saudável e que hoje a carne é água. Que não comem mais alimentos naturais como na sua infância, que até mesmo a salada era natural, sem agrotóxicos. Que se não tiver dinheiro, não tem o que comer, pois é tudo comprado e antes era tudo colhido na lavoura.

Os entrevistados atestam a sua saúde como um diferencial dos dias atuais, atribuindo tal fato à alimentação mais natural que era retirada da lavoura cultivada por eles sem uso de agrotóxicos, quando havia a legítima comida cabocla. Segundo Loiola, ${ }^{16}$ para alimentar-se de maneira saudável, é necessário conhecer a origem do alimento, além de escolher corretamente.

Colocam que os alimentos eram naturais e que hoje é tudo "químico" (alimentos industrializados). Devido a isso, ocorrem várias doenças, as quais são ocasionadas pela alimentação. No dia a dia, faziam quirera com carne de porco. Aos bebês ofereciam mamadeira com caldo de canjica, e que nunca precisaram de médicos para as crianças. Utilizavam diariamente batata doce com leite. Também relataram que as criações crioulas eram mais saudáveis, porque os animais eram alimentados com plantações feitas na lavoura sem agrotóxicos e restos de comida que também vinham da lavoura.

Os animais tinham um tempo de crescimento maior, e a utilização de hormônios não existia - por isso a carne era mais saudável, bem como a banha adquirida da preparação colonial. O óleo não era utilizado, apenas a banha de porco, porque ela oferece força ao organismo para o trabalho e na prevenção de doenças. Muitos colocaram que o óleo faz mal, que não conseguem utilizar nos dias de hoje, além de destacarem o óleo transgênico e que muitas pessoas não observam o que estão comprando no supermercado, e muitas vezes adquirem "veneno". 
A banha de porco foi considerada vilã pelos malefícios causados em termos de doenças cardiovasculares, este saber científico hoje revê a injustiça que cometeu em relação à repreensão atribuída à mesma. Os argumentos dos caboclos não remetem às justificativas científicas, mas à longevidade dos ancestrais.

Pollan ${ }^{17}$ cita, em seu estudo, que quando o índice de doenças cardíacas se elevou, os norteamericanos restringiram o uso de gorduras animais, elevando o consumo de óleos vegetais, mas tiveram mais ataques cardíacos. No entanto, não dispomos das quantidades de gorduras animais e óleos utilizados por esse grupo, e da mesma maneira sabemos que a atividade física do caboclo, na época em que os entrevistados fizeram o relato, era de um esforço físico bem maior, o que aumentava o gasto energético.

A maioria das entrevistas relatou que dificilmente eram afetados por alguma doença e, quando ocorria, utilizavam chás por eles mesmos preparados. Afirmaram que, no passado, as crianças e os adultos eram mais saudáveis que nos dias atuais e que isso se deve à modificação dos hábitos alimentares e à má preparação dos alimentos. Como colocado por uma entrevistada, um dos chás utilizados:

Pra faze cha pra ronquidão pras criança era feito uma cinza, mas de madera boa, daí pegava uma ponta de faca colocava na chicra colocava água fervendo, ai eu tapava ela um poquinho né dai ele baxava aquele pó, dai eu tirava aquela água e colocava, coava ela e colocava uma gota de querosene né conforme a idade até treis gota, conforme a idade da criança, pra toma, a criança tomava e caso de meia hora limpa aquela ronquidão.

Nos estudos de Willems, ${ }^{18}$ o caboclo era visto pelas sociedades urbanas como um "doente", um "indolente", um "atrasado", e era repudiado pelo fato de preferir os chás medicinais e curandeiros aos médicos. Os entrevistados acreditam e afirmaram que na época muitos "males" eram curados com chás medicinais. Na cultura cabocla, as mulheres mais velhas são respeitadas pelos conhecimentos que possuem, os quais são repassados de geração em geração. ${ }^{10}$

A comparação entre o "tempo antigo" e os "dias de hoje" serve para os entrevistados explicarem as relações de trocas sociais (passadas e atuais) das pessoas entre si e com a natureza da região na produção alimentar. O "tempo antigo" é idealizado. ${ }^{4}$

\section{Conclusão}

A relação que os caboclos fazem dos alimentos produzidos de forma natural com os alimentos consumidos hoje merece destaque. Vale a pena refletir que o tempo em que esses indivíduos descrevem foi um tempo em que o "milho" era produzido sem agrotóxicos e processado sem aditivos. 
A preparação e o consumo desses alimentos não desenvolviam doenças. Os caboclos percebem, sem orientação de profissionais nutricionistas, que o excesso de alimentos industrializados está diretamente ligado ao desenvolvimento de doenças. -

Os hábitos alimentares passam a dar espaço a alimentos industrializados e processados que são inseridos no prato das comunidades com maior êxito que os produtos produzidos artesanalmente e utilizados pelas famílias de outrora. Os métodos de trabalho tornam-se cada vez mais facilitados, com menos preocupação em manter a integridade do alimento. Essa situação, inúmeras vezes, acaba sendo ligada também à escolha dos alimentos, que pode estar associada aos grupos sociais onde as famílias estão inseridas, que, por sua vez, acabam adotando novos hábitos alimentares, distanciando-os das culturas em que foram criados.

Percebeu-se que algumas preparações ainda continuam sendo elaboradas, mas sofreram algumas readaptações devido à mudança do estilo de vida. Foi destacado que hoje não se tem mais tempo para a elaboração das refeições e se adquirem produtos de fácil e rápido preparo. Mesmo assim, as pessoas têm a consciência dos danos que o excesso de alimentos industrializados causa ao organismo. Afirmam que, antigamente, quando eram crianças, com a utilização de alimentos naturais, os problemas de saúde eram menores, comparados com os dias atuais. Os problemas de saúde, caso aparecessem, eram curados com chás medicinais.

No estudo realizado, conclui-se que o modo de preparo e o modo de aquisição dos alimentos se modificaram, mas costuma-se comer as mesmas preparações, o que parece indicar um novo significado da cultura cabocla do Oeste catarinense.

\section{Referências}

1. Moreira SA. Alimentação e comensalidade: aspectos históricos e antropológicos. Cienc. Cult. 2010; 62(4):23-26.

2. Proença RPC. Alimentação e globalização: algumas reflexões. Cienc. Cult. 2010; 62(4):43-47.

3. Figueroa DF. Padrões alimentares: da teoria à prática - o caso do Brasil. Revista Virtual de Humanidades 2004; 4(9):104-114.

4. Canesqui AM. Antropologia e alimentação. Rev. Saúde Públ. 1988; 22(3):207-16.

5. Murrieta RSS. O dilema do papa-chibé: consumo alimentar, nutrição e práticas de intervenção na Ilha de Ituqui, baixo Amazonas, Pará. Rev. Antropol. 1998; 41(1):97-159.

6. Barbosa L. Feijão com arroz e arroz com feijão: o Brasil no prato dos brasileiros. Horizontes Antropológicos 2007; 13(2):87-116.

7. Alessi NP. Conduta alimentar e sociedade. Medicina 2006; 39(3):327-32.

8. Maciel ME, Menasche R. Alimentação e cultura, identidade e cidadania. Você tem fome de quê? 
Democracia Viva. Especial Segurança Alimentar 2003; 16:3-7.

9. Lucas JF, Perin O. Manifesto caboclo. Disponível em: http://encipecom.metodista.br/mediawiki/ images/1/1a/GT3-_09__Manifesto_Caboclo-varios.pdf.

10. Renk A, Savoldi A. Comida e gênero num contexto de etnicização. Fazendo Gênero 8 - Corpo, Violência e Poder; 25-28 ago. 2008; Florianópolis, Santa Catarina.

11. Tonial SR. Desnutrição e obesidade: faces contraditórias na miséria e na abundância. Recife: IMIP; 2001. 189 p.

12. Mintz SW. Comida e antropologia: uma breve revisão. RBCS 2001; 16(47):31-42.

13. Marciel ME. Cultura e alimentação ou o que têm a ver os macaquinhos de Koshima com BrillatSavarin? Horizontes Antropológicos 2001; 7(16):145-156.

14. Fischer RMB. Foucault e a análise do discurso em educação. Cadernos de Pesquisa 2001; (114):197-223.

15. Magalhães C. Comida de comer comida de pensar. Cadernos de Debate. 1995; 3:29-57.

16. Loiola R. O futuro da comida. Revista Galileu 2010. Disponível em: http://revistagalileu.globo. com/Revista/Common/0,EMI129201-17773,00-O+FUTURO+DA+COMIDA+TRECHO.html

17. Pollan M. Em defesa da comida: um manifesto. Rio de Janeiro: Intrínseca; 2008.

18. Willems E. O problema rural brasileiro do ponto de vista antropológico. São Paulo: Secretaria de Agricultura, Indústria e Comércio do Estado; 1944. 